\title{
Supporting Information for "Sensorized Foam Actuator with Intrinsic Proprioception and Tunable Stiffness Behavior for Soft Robots"
}

Saravana Prashanth Murali Babu*1, Francesco Visentin ${ }^{1}$, Ali Sadeghi ${ }^{1}$, Alessio Mondini ${ }^{1}$, Fabian Meder $^{1}$, and Barbara Mazzolai*1

${ }^{1}$ Affiliation not available

May 5, 2021

\author{
Abstract \\ This Supporting information includes: \\ 1. Component Selection and Performance of SFA \\ 2. Actuator Manufacturing and Preparation of Conductive Ink \\ 3. Average Thickness of Conductive Coating layer on PU Foam \\ 4. Time Response of the Actuator in Different Modes \\ 5. Characterization and Experimental Setup \\ 6. Measurement and Data Analysis \\ 7. Design Specifications of Soft Robotic Applications \\ 8. Supporting Video \\ Corresponding author Email: saravanaprashanth@outlook.com, barbara.mazzolai@iit.it
}

\section{Component Selection and Performance of SFA}


Components

Materials and devices

Copper plate adhesive

Silver epoxy

Support frame

Foam

Fiber-reinforced skin

Paper sheets

Wire

Pneumatic connector

Laser cutter

Foam cutter

Electronics and Mechanical components

Controller

Electro-valves

Voltage divider circuit

Data acquisition system

Oil lubricated rotary vane pump

Pneumatic pump (approx. $+50 \mathrm{kPa}$ to $-50 \mathrm{kPa}$ )
Company/Material

3M 1245 Tape

Chemtronics, CW2400

Delrin or POM

Modulor, GmbH, 033035

3M, Scotch 1900

Cellulose fibers

Insulated copper wire

Silicone and PP (polypropylene)

Versalaser ULS 3.0

Custom-made (wire-cut)

Custom-made

Parker, X-valve

Custom-made

NI USB 6219

MM56p2, D.V.P Vacuum Technology s.r.l

Parker, Micro diaphragm pump

Table 1: Required components needed to build the integrated SFA. 


\begin{tabular}{|c|c|c|}
\hline $\begin{array}{c}\text { Component (parameters) } \\
\text { Area }\end{array}$ & Value & Unit \\
\hline Form core & 2168.7 & $\mathrm{~mm}^{3}$ \\
\hline $\begin{array}{l}\text { Module weight } \\
\text { Assembled SFA }\end{array}$ & 34 & g \\
\hline $\begin{array}{c}\text { Actuation } \\
\text { Positive pressure }\left(\mathrm{P}_{\mathrm{p}}\right) \\
\text { Negative pressure }\left(\mathrm{N}_{\mathrm{p}}\right)\end{array}$ & $\begin{array}{l}{[10-40]} \\
{[10-90]}\end{array}$ & $\begin{array}{l}\mathrm{kPa} \\
\mathrm{kPa}\end{array}$ \\
\hline $\begin{array}{c}\text { Actuation period } \\
\text { Active compression }\end{array}$ & 4000 & $\mathrm{~ms}$ \\
\hline $\begin{array}{c}\text { Relaxation time }\left(\mathrm{T}_{\mathrm{r}}\right) \\
\text { Mode } 1\left(\text { only } \mathrm{N}_{\mathrm{p}}\right) \\
\text { Mode } 2\left(\text { both } \mathrm{N}_{\mathrm{p}} \text { and } \mathrm{P}_{\mathrm{p}}\right)\end{array}$ & $\begin{array}{c}5.35 \\
1.5\end{array}$ & $\begin{array}{l}\mathrm{S} \\
\mathrm{S}\end{array}$ \\
\hline $\begin{array}{c}\text { Relative resistance }\left(\Delta \mathrm{R} / \mathrm{R}_{\mathrm{O}}\right) \\
\text { Passive compression (skin) } \\
\text { Active (vacuum) }\end{array}$ & $\begin{array}{l}64 \\
95\end{array}$ & $\begin{array}{l}\% \\
\%\end{array}$ \\
\hline Maximum force $\left(\mathrm{F}_{\max }\right)$ & $235 @-90$ & $\mathrm{~N} @ \mathrm{kPa}$ \\
\hline
\end{tabular}

2. Actuator Manufacturing and Preparation of Conductive Ink 

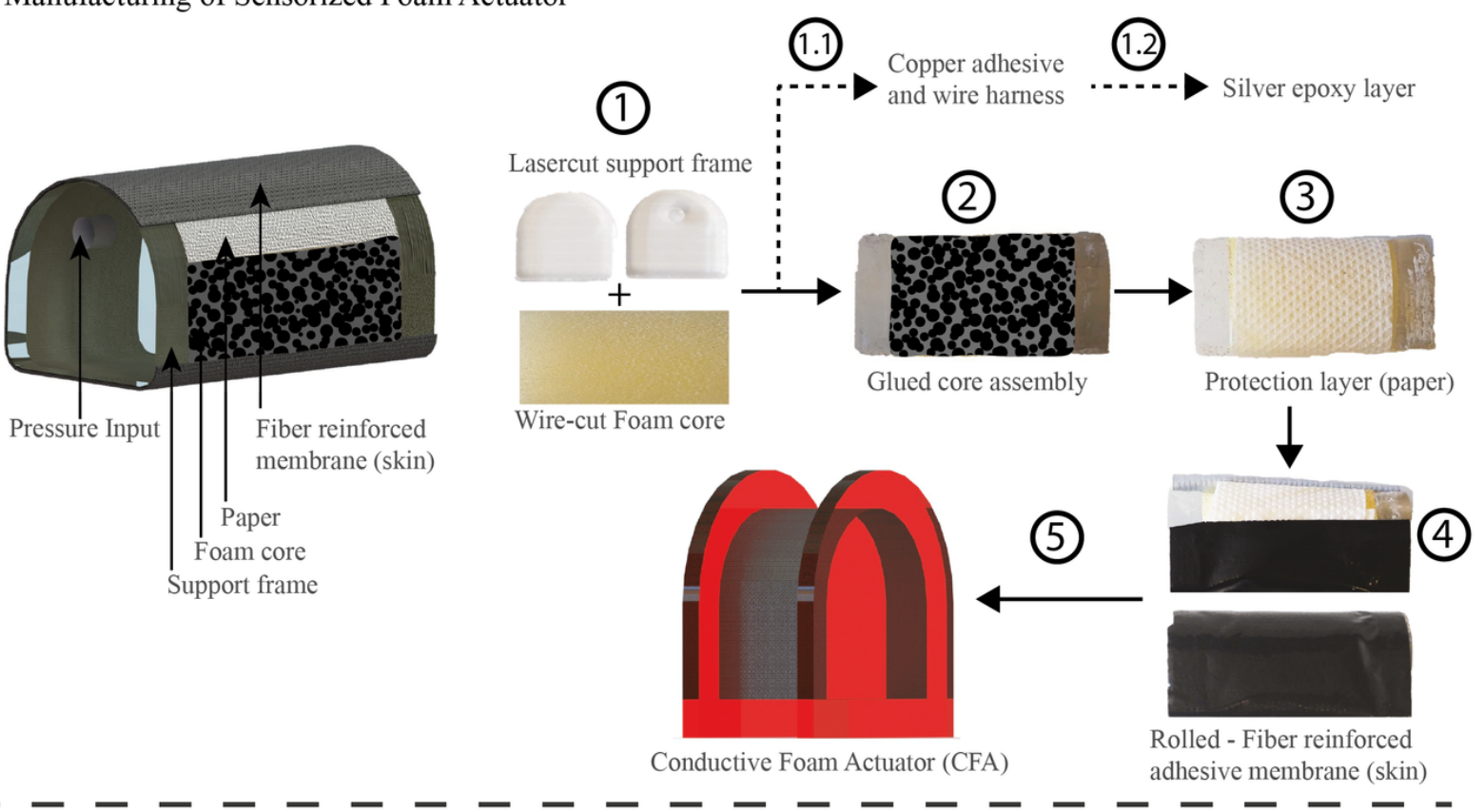

B) Preparation of conductive ink

Step 1

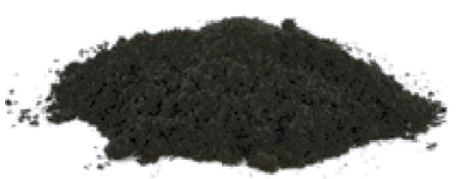

Carbon (Vulcan, XCRF), $1 \mathrm{~g}$

Step 2

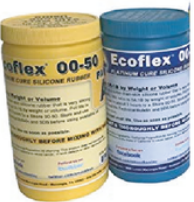

Prepolymer (Ecoflex - 0050, Smooth-ON), 4g (1:1)

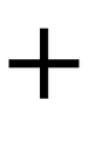<smiles>Cc1ccccc1</smiles>

Stir 15 min

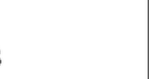

Stir $15 \mathrm{~min}$

Toluene, $18 \mathrm{~mL}$

\section{Conductive Ink}

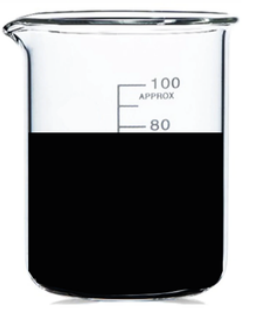

Stir $25 \mathrm{~min}$

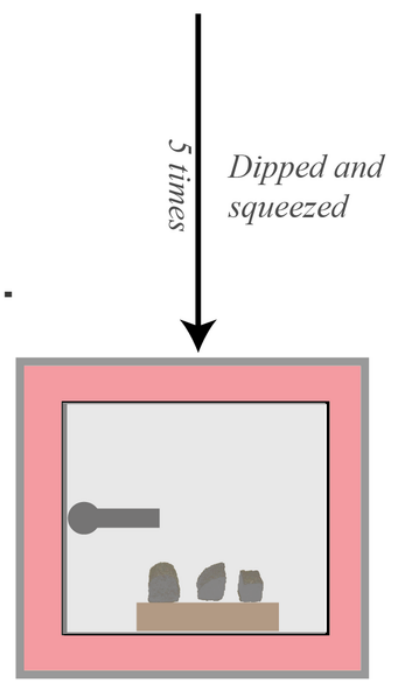

Conductive Foam

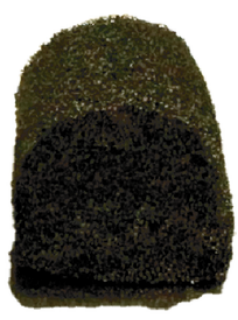

Dome

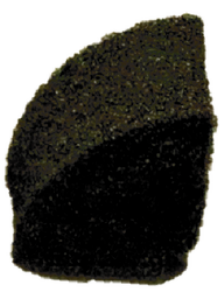

Triangle

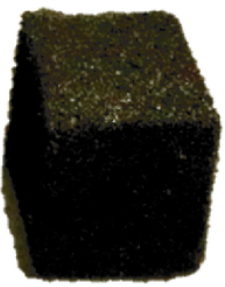

Square
Oven at $120^{\circ} \mathrm{C}$ for 60 minutes

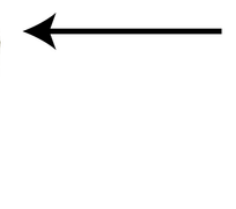

-

Figure 1: A) Manufacturing steps involving easy-to-do laser cut of the support structures and wire-cut conductive foam for batch manufacturing process. Glued core assembly comes with support frame sandwiched with copper plate (Advanced Leicester) and a layer of silver epoxy (Chemtronics). Later part is then encapsulated with a layer of paper and fiber reinforced adhesive skin. The same procedures are followed for different size and shape of the actuator. Final step is to connect the one end of the actuator to the pressure 


\section{Average Thickness on Conductive Coating Layer on PU}

A)
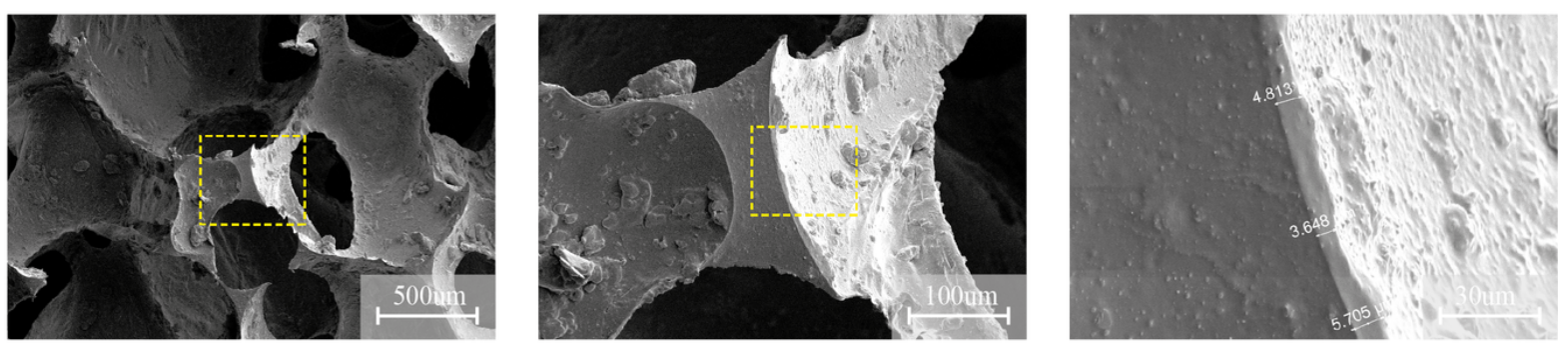

B)
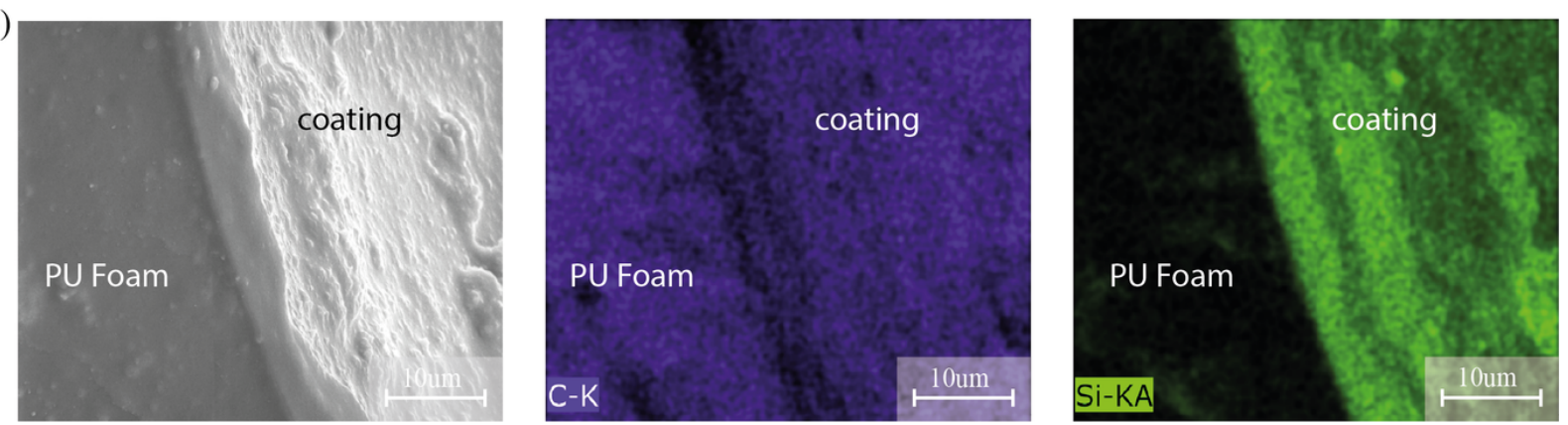

Figure 2: A) Scanning electron microscopy (SEM) image of the coated conductive foam. Samples were prepared by sectioning the conductive foam and observation in the SEM without further sputtering showing an average thickness of the coating layer of $\sim 4.29 \pm 0.5 \mu \mathrm{m}$ over the PU foam. B) Microanalysis of the conductive foam was performed clearly showing carbon ' $\mathrm{C}$ ' in coating and $\mathrm{PU}$ foam whereas silicon ' $\mathrm{Si}$ ' is only present in the coating due to the silicone elastomer in the conductive ink.

\section{Time Response of the Actuator in Different Modes}


A)

MODE $1(\mathrm{M} 1)$
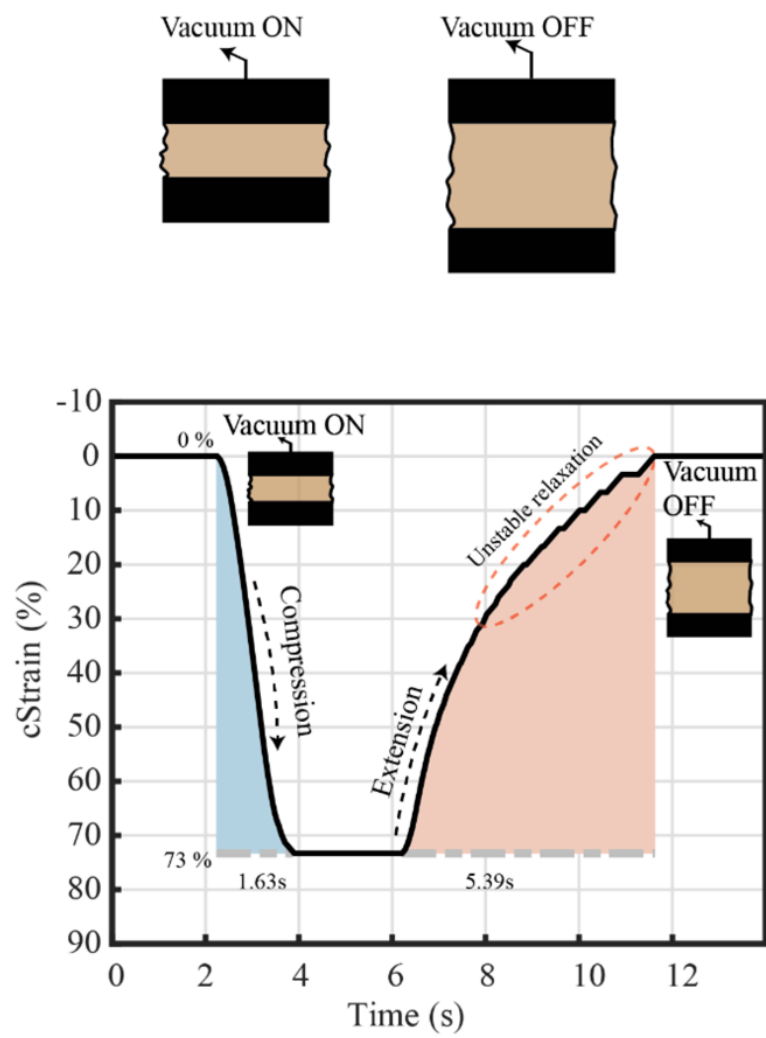

B)

MODE 2 (M2)
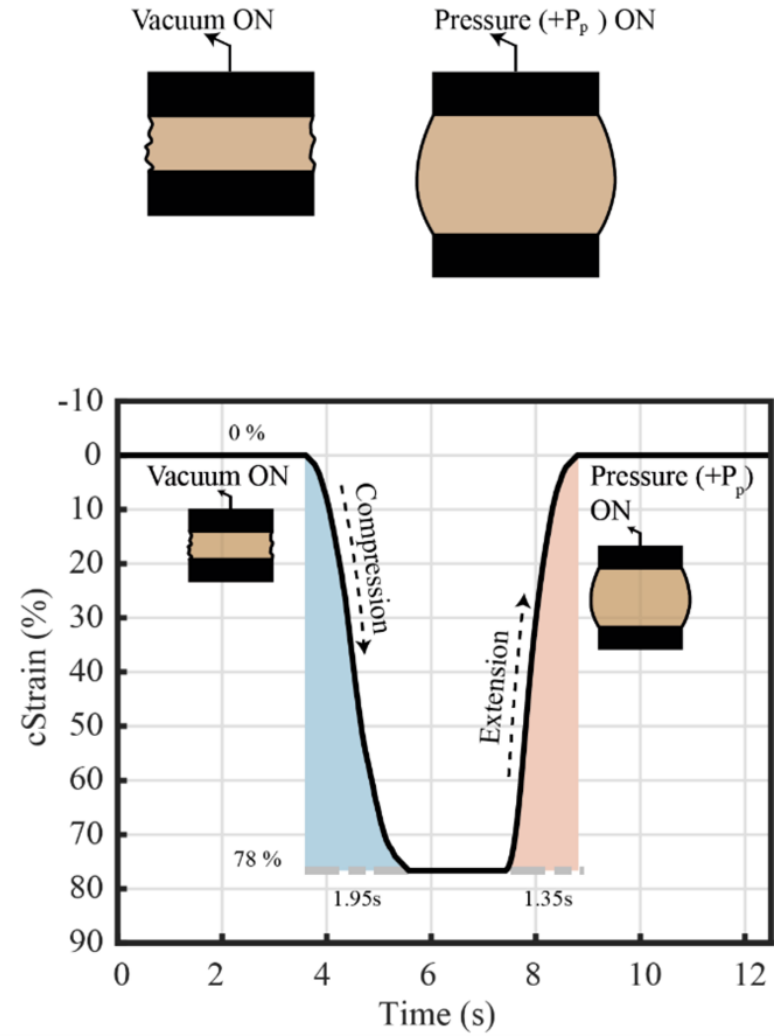

Figure 3: Response of the SFA to the various active actuation modes. A) Mode 1 actuation (vacuum @ $-90 \mathrm{kPa}$ followed by passive decompression) showing a slower response during relaxation phase with some unstable zones while recovering. B) Mode 2 actuation (vacuum @ $-90 \mathrm{kPa}$ followed by active decompression using $10 \mathrm{kPa}$ ) showing a response that is five times faster and more stable. Plots are an average over 20

cycles. Mode 2 is faster and more accurate than mode 1 which is five times slower with some instability during the relaxation phase.

\section{Characterization and Experimental Setup}




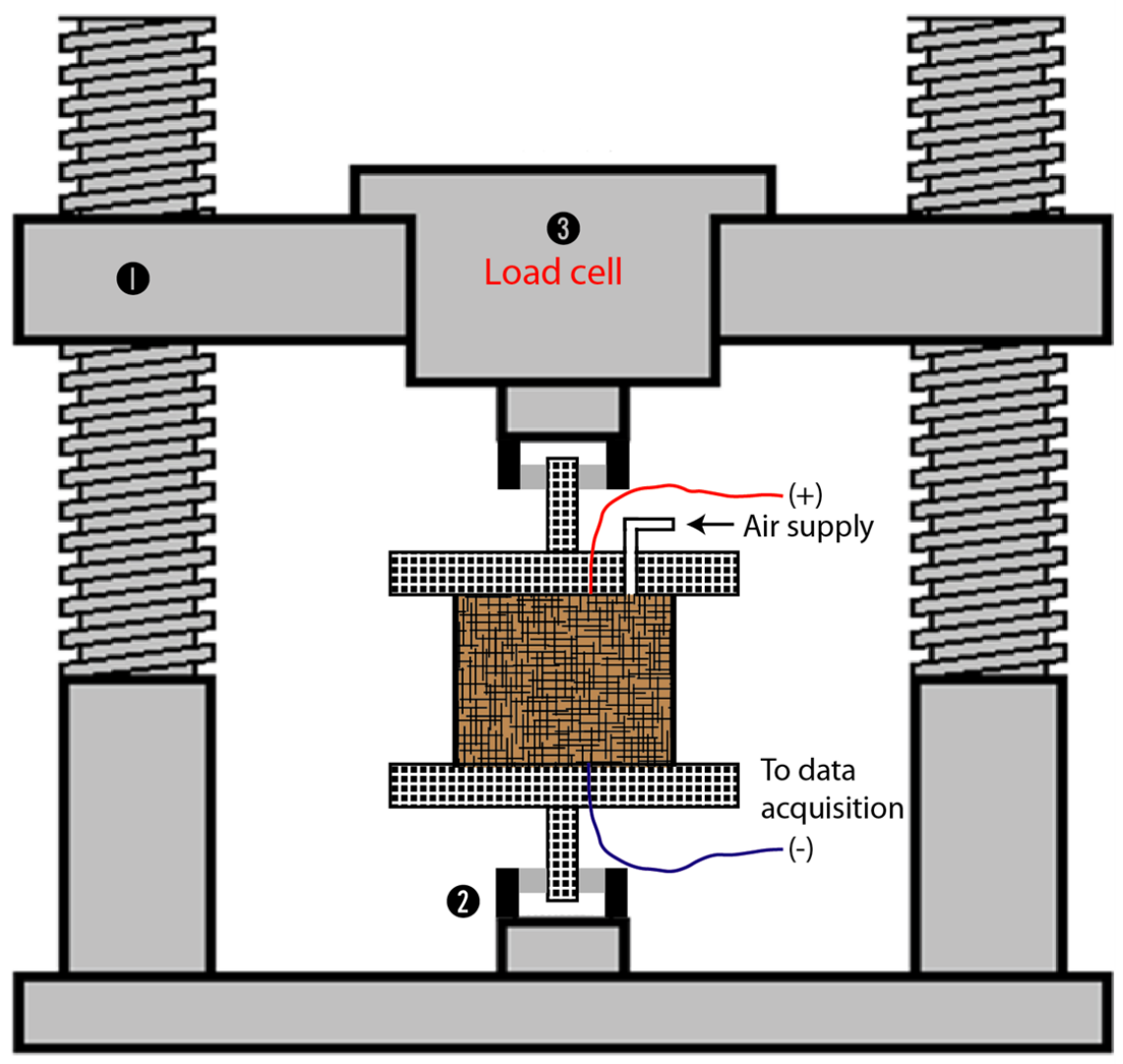

Figure 4: Illustrative setup of static measurement device (zwick/roell, Z005) used for characterization experiments. 1) Movable linear stage used to compress the actuator module in a constant speed of $30 \mathrm{~mm} / \mathrm{min}$ without any additional disturbance. 2) Mechanical pressurized clamps with gripper in order to hold the actuator modules in place preventing from mechanical instability. 3) Load cell of $1 \mathrm{kN}$ from Zwick and Roell to measure the extension or pulling force of the actuator under different circumstances such as variable pressure, different size and mode of actuation. The sequence of experimental procedure are as follows, first the pressure input is turned on (actuated) which pulls the actuator along with the loadcell causing increase in the force and the linear stages compresses down to $20 \mathrm{~mm}$ displacement and then pulled up to the original state. This is repeated for 11 cycles for every characterization experiments. 


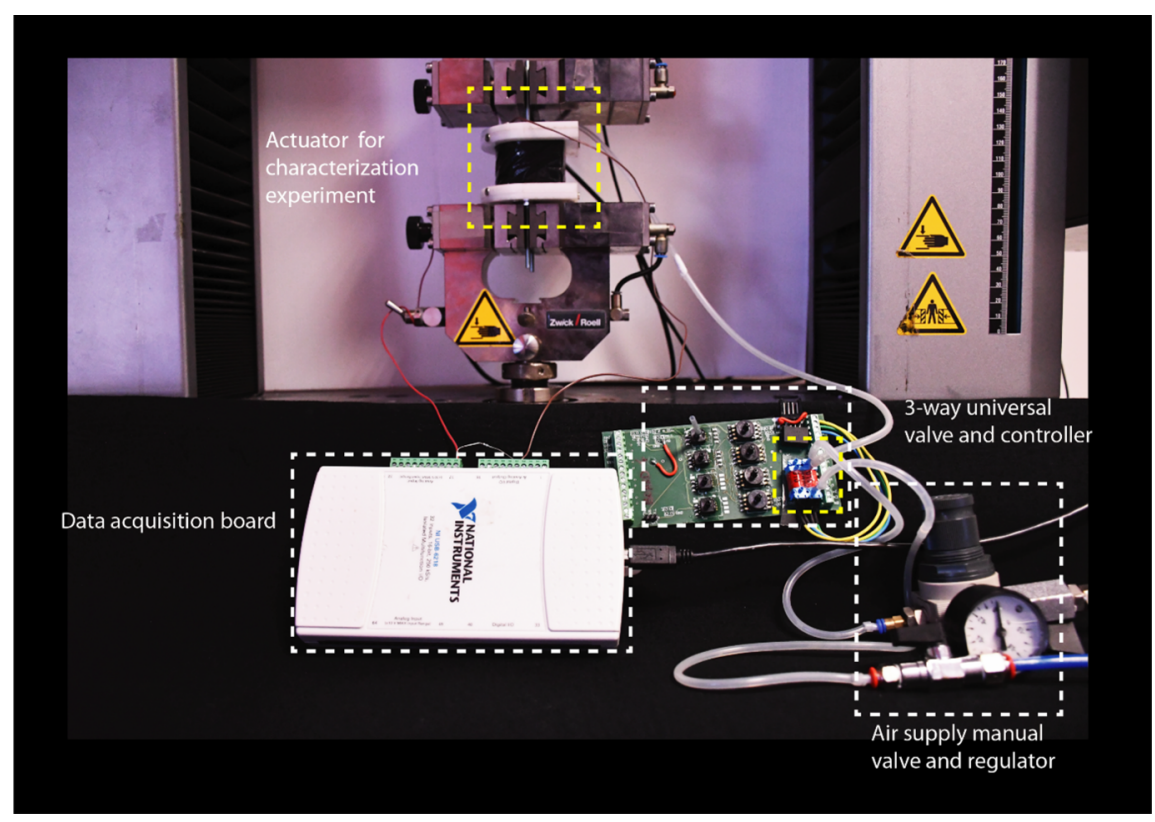

Figure 5: Instrumentation setup for SFA experiments. NI USB 6229 DAQ used for data acquisition of change in voltage from the actuator to the voltage divider circuit, later post processed to visualize relative resistance. Air supply channel for both positive and negative pressure with manual valve and regulator. 3-way universal electro valves (yellow dotted lines) are used to control the input pressure using the controller board which actuates the actuator based on the driven square wave signal sequence from the computer. Characterization and experimental setup are described in figure S4.

\section{Measurement and Data Analysis}

\section{Porosity calculation:}

By considering the sample of total volume as $V_{t}$. Defining the solid phase to be of volume $V_{s}$, and the volume of the pore phase (the holes) to be $V_{p}$, with $V_{t}=V_{s}+V_{p}$. The volume fraction of the pore phase or porosity is denoted by $\varphi=V_{p} / V_{t}$. The solid volume fraction is then $1-\varphi \cdot{ }^{[1]}$

By assuming these values, (assumptions were made from the average pore size and that of the solid modelling analysis)

Volume in solid phase $\left(\mathrm{V}_{\mathrm{s}}\right)$ is $24102.88 \mathrm{~mm}^{3}$

Volume in pore phase $\left(\mathrm{V}_{\mathrm{p}}\right)$ is $16068.5 \mathrm{~mm}^{3}$

Using the above defined information, the porosity is calculated to be $\varphi=0.66$

\section{Passive actuation mode:}


A

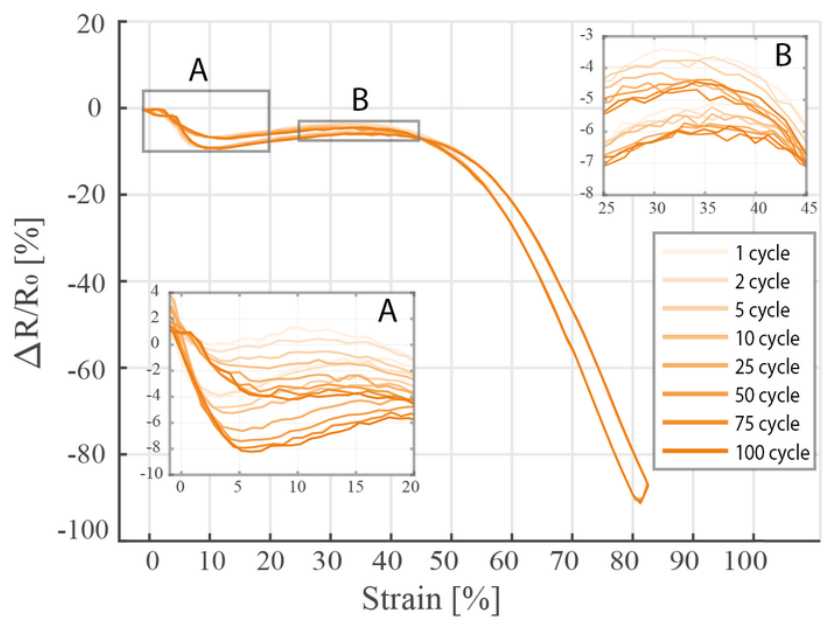

B

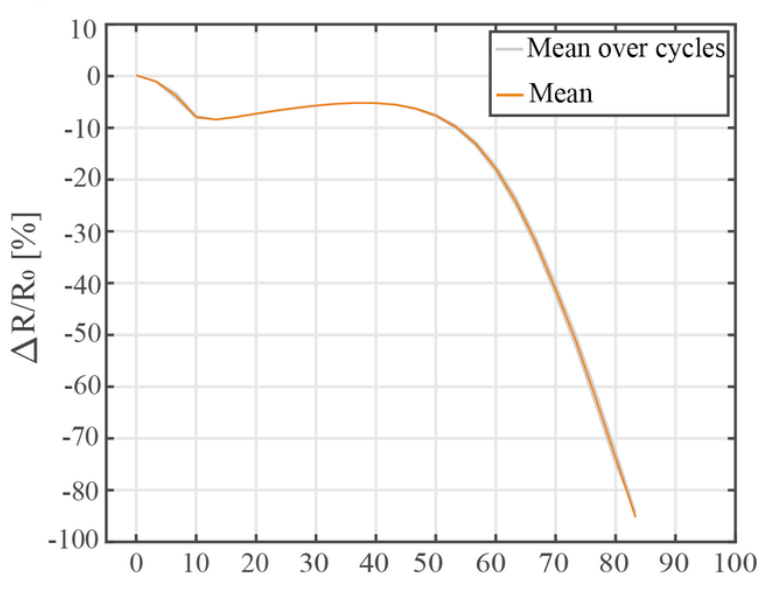

Figure 6: A) Resistance change at selected cycles (1 - 100). The zoomed-in box 'A' show a large drift in the sensor data in a strain interval of $0 \%$ to $20 \%$. The zoomed-in box 'B' show a small drift in sensor data in a strain profile of $25 \%$ to $45 \%$. B) Hysteresis of the actuator during passive actuation mode and the mean over cycles with a small drift error of $6 \%$.

\section{Active actuation mode:}


A

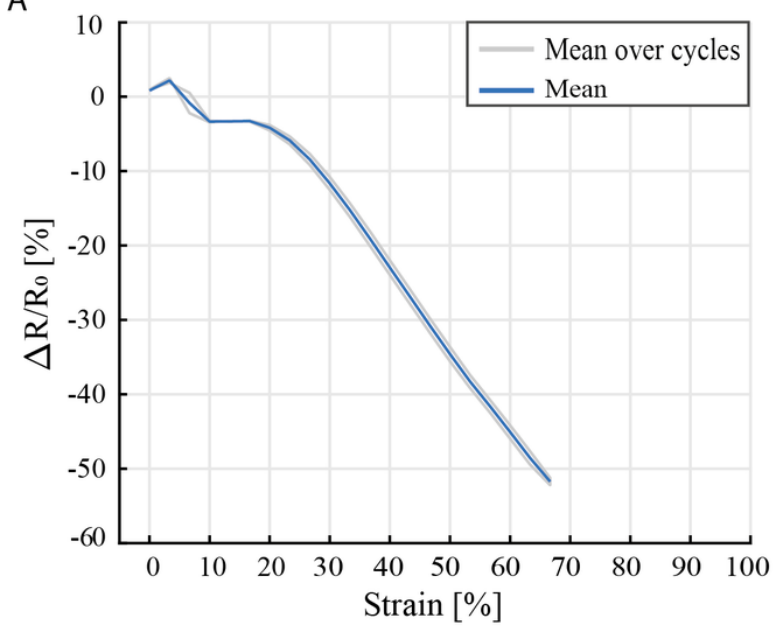

C

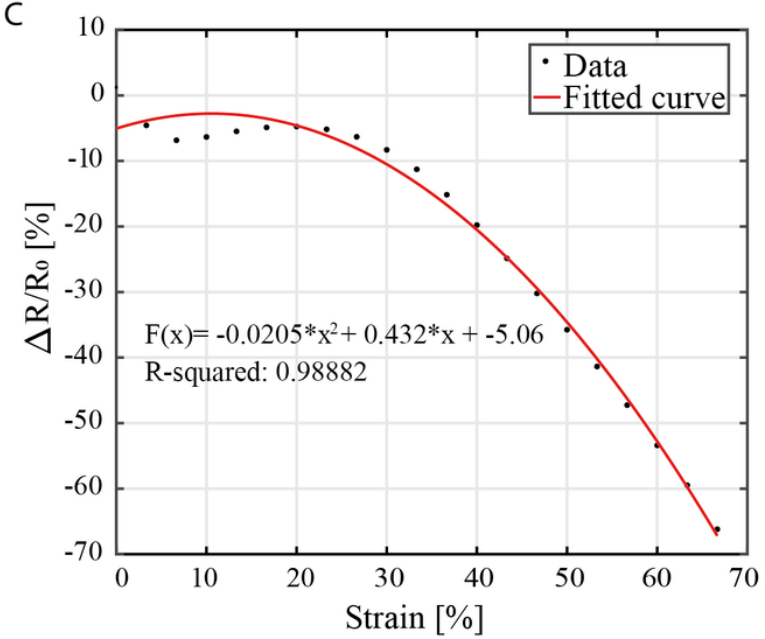

B

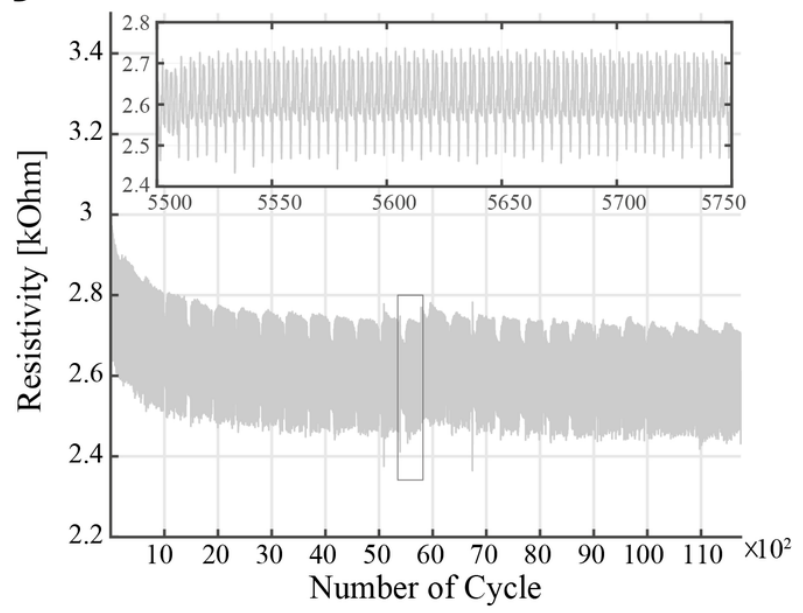

D

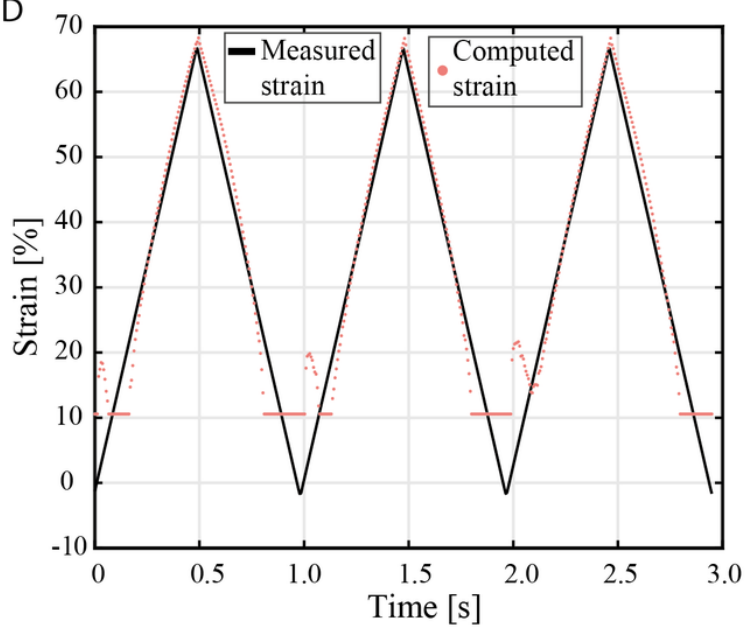

Figure 7: A) Hysteresis of the actuator during passive actuation mode and the mean over cycles with a small drift error of less than $4 \%$. B) Cyclic test for more than 10000 to confirm the robustness and reliability of the sensorized foam. C) Fitting curve of the relative resistance data with the given function showing an accuracy value of $\mathrm{R}^{2}$ equal to 0.988 . D) Evaluation of the accuracy of the fitting used to retrieve the strain from the changes in the relative resistivity. As it is possible to notice, the data show a linear relationship (error $<$ $15 \%$ ) for strain larger than $22 \%$ while for lower compression value the data deviate from the fitting with larger errors (40\%). The relationship between the real and the computed strain value is plotted in Figure $2 \mathrm{E}$.

$\begin{array}{ccccc}\text { Displacement }(\mathrm{mm}) & \text { Strain }(\%) & \text { Force @ }-30 \mathrm{kPa}(\mathrm{N}) & \text { Force @ }-60 \mathrm{kPa}(\mathrm{N}) & \text { Force @ }-90 \mathrm{kPa}(\mathrm{N}) \\ 0 & 0 & 0 & 0 & 0 \\ 5 & 17 & 24 & 31.5 & 92 \\ 10 & 34 & 33 & 48 & 150 \\ 15 & 50 & 42 & 61 & 190 \\ 20 & 70 & 68 & 88 & 230\end{array}$

Table 3: Force value for the active compression case under variable pressure inputs with displacement interval of very $5 \mathrm{~mm}$ up to $20 \mathrm{~mm}$. 

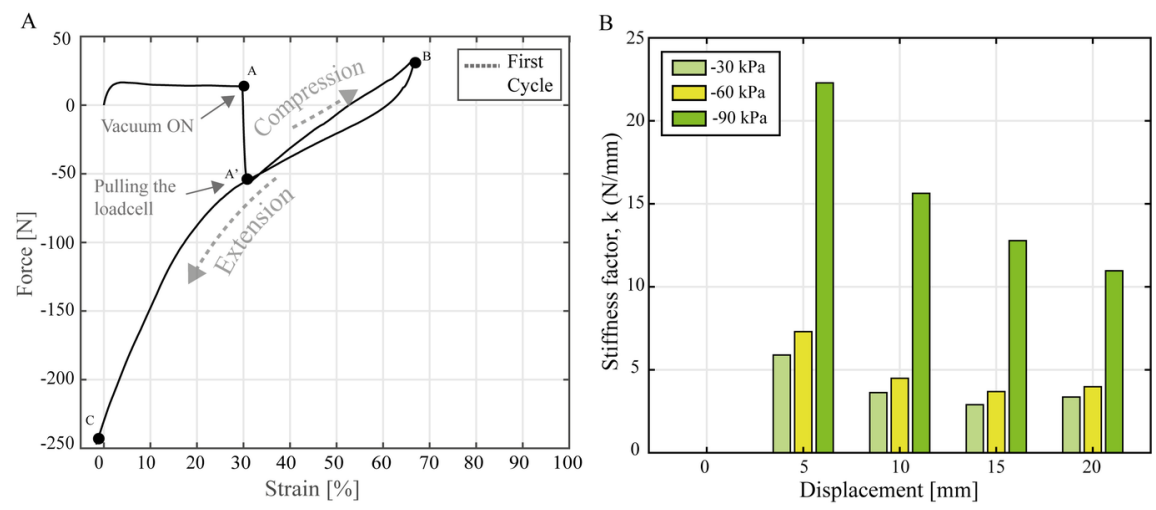

Figure 8: A) Force reading with the initial response of the actuator before applied vacuum (A) and after applied vacuum $\left(\mathrm{A}^{\prime}\right)$ and from here it compresses down to $70 \%$ of the strain upto point B and pulled back to the initial position (c).Thereafter goes with the cyclic compression and extension phase of the actuator. This is to support the result shown in Figure 3A. B) Tunable stiffness of the actuator at multiple pressure input $(-30,-60,-90) \mathrm{kPa}$ exhibiting increase in stiffness factor $(\mathrm{k})$ during extension profile of the sensorized actuator. This is to support the result shown in Figure 3D and the corresponding value of ' $\mathrm{k}$ ' stiffness factor is shown in the table below Table S3.

$\begin{array}{ccccc}\begin{array}{c}\text { Displacement } \\ (\mathrm{mm})\end{array} & \text { Strain } & \mathrm{k} @-30 \mathrm{kPa} & \mathrm{k} @-60 \mathrm{kPa} & \mathrm{k} @-90 \mathrm{kPa} \\ 0 & (\%) & (\mathrm{N} / \mathrm{mm}) & (\mathrm{N} / \mathrm{mm}) & 0 \\ 5 & 0 & 0 & 0 & 22.3 \\ 10 & 17 & 5.9 & 7.3 & 15.6 \\ 15 & 34 & 3.6 & 4.5 & 12.8 \\ 20 & 50 & 3 & 3.7 & 11\end{array}$

Table 4: Stiffness value for the active compression case under variable pressure inputs with displacement interval of very $5 \mathrm{~mm}$ up to $20 \mathrm{~mm}$.

\section{Design Specifications of Soft Robotic Applications}


A) Compression piston-like actuator

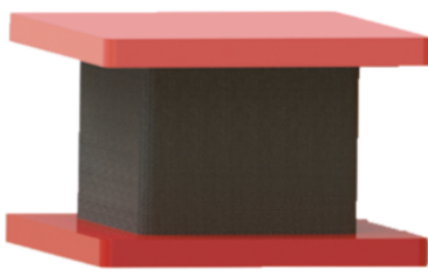

Square shaped
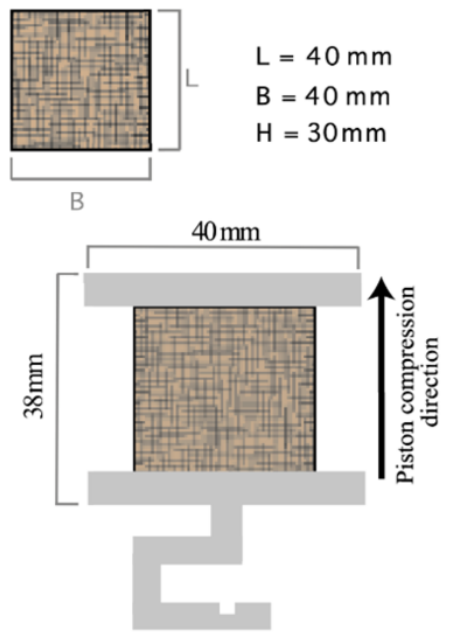

B) Inchworm-like crawling locomotion

C) Trunk like robotic manipulator

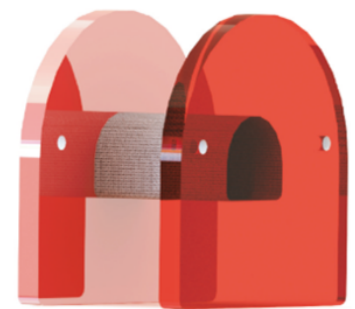

Arc dome shaped

I

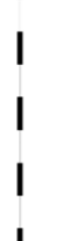

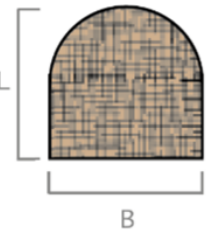

$\mathrm{L}=15 \mathrm{~mm}$

$B=15 \mathrm{~mm}$

$\mathrm{H}=30 \mathrm{~mm}$
I

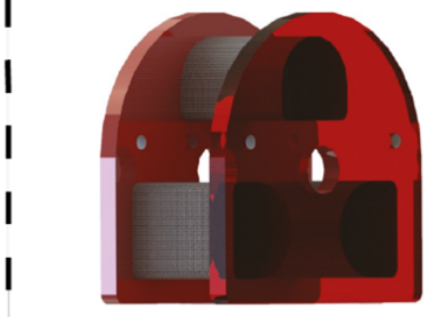

3x Arc dome shaped

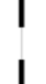

3x Arc dome shaped
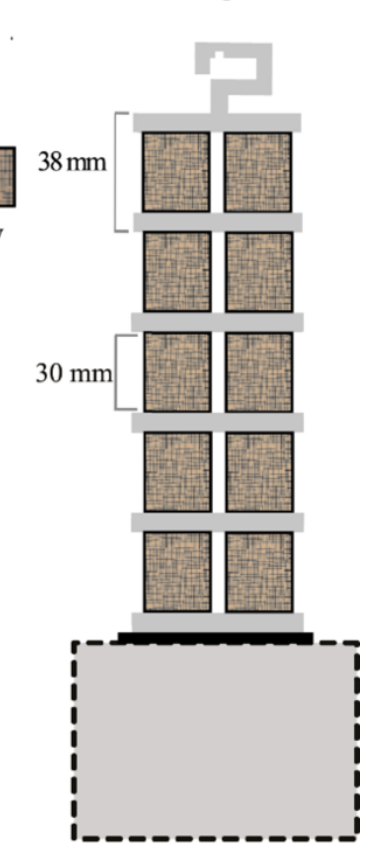

Figure 9: Illustrative description and details of the robot built using SFA's and their details. A) compression piston-like actuator built using the design of square shaped large sized actuator. The hanger in the bottom was printed using SLA 3D printer (Formlab 2, Formlabs inc.) in order to place a hanger and step increase in the load from no load up to $6 \mathrm{~kg}$. B) crawling locomotion robot was built using the design of arc dome shaped small sized actuator. Each of the them are connected in series to forms a modular structure for inchworm-like crawling locomotion. $1^{\text {st }}, 3^{\text {rd }}$ and $6^{\text {th }}$ are the one measuring the relative resistance during every gait cycle. C) Trunk-like robotic manipulator was built in a different configuration by arranging three arc dome-shaped small sized actuators adjacent to one another at an angle $90^{\circ}$ parallel and perpendicular to each other. This configuration helps the module to rotate, compress and extend the actuator. From the top $1^{\text {st }}$, and $4^{\text {th }}$ were the one marked for measuring the change detected during manipulating under load and no load condition.

\section{Supporting Video}

Rich media available at https://youtu.be/Po7L3XCLS9k

Rich media available at https://youtu.be/1zDKgZGjjFk

Rich media available at https://youtu.be/4mre2MZGsT0 
Rich media available at https://youtu.be/3L1SMwj5Xcs

Rich media available at https://youtu.be/INxoPVHgiZO

Rich media available at https://youtu.be/U99UW04szEA

Rich media available at https://youtu.be/AlT_U22d3aI

Rich media available at https://youtu.be/QiJCaeQ4EaQ

\section{References}

[1]E. J. Garboczi, D. P. Bentz, N. S. Martys, Methods in the Physics of Porous Media 1999, 35, 1. 